\title{
Methodological approach to creation of the 3D model of an oval-shaped open pit mine
}

\author{
Serik Moldabayev ${ }^{1}$, Bolatbek Rysbaiuly ${ }^{2}$, Zhanat Sultanbekova ${ }^{1}$, and Nurzhigit Sarybayev ${ }^{1 *}$ \\ ${ }^{1}$ Satbayev University, Institute of Geology, Oil and Mining, 22 Satbayev St., 050013 Almaty, Republic \\ of Kazakhstan \\ ${ }^{2}$ International University of Information Technologies, Information Technologies and Mathematic \\ Modelling Department, 8 Manas St., 050000 Almaty, Republic of Kazakhstan
}

\begin{abstract}
A 3D model of optimal contours phased development of ovalshaped open pit mines is proposed in the article. It is assumed that with enough accuracy the volumetric contour of the open pit mine is interpolated by an elongated elliptic hyperboloid. The calculation formulas for mineral resources are derived and optimal volumes of overburden are determined depending on the mining phase. In this case, the total number of mining phases is set in advance. The stripping ratio is used as a quality criterion of the optimization task. The problem of optimal control is solved using the Bellman function in dynamic programming. All the necessary calculation formulas are obtained in the final form by solving the optimization problem. Their simplicity and substantiation of each conclusion ensure that the results of this study can be successfully applied in practical calculations of the design and planning of mining operations in open pit mining.
\end{abstract}

\section{Introduction}

One of the constraints of implementing innovative technologies in open pit mining is the lack of a methodology for their implementation in design practice. We considered the case of round-shaped mineral occurrences when creating a 3D model for the phased development of the open pit contours $[1-3]$. The open pit mine turned out to have a form of a truncated cone, which is characteristic mainly in mining of kimberlite deposits. It was possible to solve this problem on digital models of open pit mines using phased contours of an open pit mine along the horizontal sections of a one-dimensional spline of the second order, and a two-dimensional spline in depicting the lateral surfaces of the ore body in 3D modelling. The inclination of the open pit edges by mining phases of steeply dipping open pit mines has been taken into account by establishing an optimal radius of the contours of the lateral surfaces on each of them while optimizing the volumes of overburden and ore, as well as the step-by-step determination of the stripping ratio. However, practice shows that most of the open pit mines are oval.

Modern design of production at a mining enterprise, planning and allocation of resources are based on mathematical programming models. In practice, the optimal solution

\footnotetext{
${ }^{*}$ Corresponding author: moldabaev_s_k@mail.ru
} 
cannot be achieved without considering all possible combinations and permutations of the extraction sequence. Methods of studying operations have limited application in large-scale open pit mining operations, as the number of variables becomes too large. A scientific work [4], in which a hybrid basis for simulation of the problem of open pit mining planning has been developed and tested, was of great interest in solving this project's tasks. The article investigates the dynamics of the geometry (form) of open pit mining and the subsequent movement of the material in the form of a continuous system described by time-dependent differential equations.

The continuous compact action simulator is implemented in the MATLAB using a modified elliptical section to model the development of the geometry of open pit mining in time and space. Discrete simulator of open pit mining DOPS simulates the periodic expansion (development) of the front (open pit field) of open pit mining. The functional approximation of the discrete modeling of the open pit edges represents means of converting a set of partial differential equations (PDE), taking into account the dynamics of open pit mine formation, to the system of ordinary differential equations (ODE). Numerical integration using the Runge-Kutta scheme gives the trajectory (path of development) of the geometry (form) of the open pit field over time with the appropriate material volume and the net present value NPV of the extraction operation. An example of a study of an iron ore mine with 114000 blocks was conducted to verify and validate the model. The optimum pit boundaries were obtained using the Lerchs-Grossman algorithm. The best option of the annual schedule, generated by the bundle node in Whittle Four-X yielded, brought a net present value of NPV of $\$ 449$ million for 21 years of mine operation at a discount rate of $10 \%$ per annum. Authors of the article believe that the model of hybrid modeling is the basis for future studies in an interactive mode based on targeted intellectual activity.

A standard approach of designing open pit mining operations, as a rule, implements the process of open pit mine optimization, following the main planning mode within a certain final contour of the mine. As a result, the mine operates at a higher stripping ratio during the initial period and moves towards a lower ratio to the end of the operation term of the mine. The consequence of this is the annual production schedule, which does not contribute to maximizing the net present value (NPV). In this case, while selecting schemes, the Pushback approach [5] becomes practical and can increase the NPV of the project. The Pushback method minimizes the stripping ratio in the early years and delays acquiring some equipment until late in the operation term of the mine. The results of the research show that the project NPV can be increased by using the Pushbacks by delaying and leveling the costs of equipment and overburden excavation, with the maximum quality improvement required by the processing plant.

Approaches to solving the problem of operational planning of open pit mining operations with the dynamic distribution of technological vehicles, as described in a scientific work [6], will be useful when describing the dynamics of the relocation of the working zone along steep open pit edges. A hybrid algorithm, developed and tested in real conditions, combines the characteristics of two metaheuristics: Randomized Adaptive Search Procedures and General Variable Neighborhood Search.

The described models allow determining some of the desired parameters of the open pit mine during the technical-economic justification phase in the first approximation. Specially developed engineering methods of calculation are applied for open pit fields of elongated form, which have found practical application in practice of open pit design [7 - 12].

The use of optimization for planning and determining the best alternatives to data processing opens great opportunities for potential increase in value as shown in a work [13]. However, the main result is that the use of only initial and final conditions and fixed boundary values can lead to modes that are impractical when taking into account the actual limitations of the mining system. Therefore, it is important to include the considerations 
proposed in the planning process.

The scientific work [14] presents an integer programming (IP) model that generates open pit projects in accordance with the requirements of the ore reserve, as an extension of the classical optimization models for planning of mining. A set of new binary variables is introduced for this purpose, representing blocks that can be taken as an open ore reserve, in addition to mining and processing decisions. The model was encoded and tested in a set of standard copies, which indicates very encouraging results in the creation of schedules (modes) of mining blocks.

The open pit mine production scheduling problem is proposed to be solved using a new metaheuristic technique known as local branching in the study [15]. Authors combine local branching with a new adaptive branching scheme to speed up the search process and develop heuristics to create an initial feasible solution quickly. Although the minimum requirements are rarely considered in the literature, this method provides almost optimal solutions for a series of conceptually generated data sets.

Testing of the developed technology for safe intensive development of working zones along steep open pit edges on the digital model of the Lomonosov iron ore mine showed that there are reserves for minimizing stripping volumes in the phased mining of steeply dipping mineral occurrences without the formation of temporarily non-operating open pit edges [16, 17]. A methodology was developed to optimize the phased volumes of overburden and ore on the 3D model of an oval-shaped open pit mine in order to improve the design quality of this technology.

\section{Material and methods}

\subsection{Characteristics of oval shaped mineral occurrence}

We should consider the case when the mineral occurrence has an oval shape. We assume that the boundary of this region is depicted by an elongated elliptic hyperboloid. The elongated axis of the ellipsoid is depicted as a longitudinal, and perpendicular to it, axis of the elliptical hyperboloid will be the transverse axis. The horizontal cross section of hyperboloid is ellipse, the largest axis of which coincides with longitudinal direction (Ox axis), the smallest axis of hyperboloid coincides with transverse direction of ore shoot (Oy axis). The origin is located in the center of uppermost ellipse, $O z$ axis passes through it vertically downwards (Fig. 1). After fulfillment of necessary preliminary conditions, volumetric surface of ore shoot would be described by the following equation:

$$
\frac{x^{2}}{a^{2}}+\frac{y^{2}}{b^{2}}=\frac{z^{2}}{c^{2}}+1 \text {. }
$$

On uppermost boundary of ore shoot $z=0$. Horizontal cross section of this surface with plane $z=0$ is described by following expression:

$$
\frac{x^{2}}{a^{2}}+\frac{y^{2}}{b^{2}}=1 \text {. }
$$

It is assumed that this cross section is $\mathrm{n}$ extended ellipse, largest axis of which is located on $O x$ axis, with $a \gg b$ (Fig. 2). The area of the figure would be determined by limiting line (2). We should switch to polar coordinates:

$$
x=\operatorname{arcos} \varphi, y=b r \sin \varphi .
$$

We obtain an equation of ellipse in polar coordinates system (3) by putting into equation (2). It is written in the form $r=1$. 


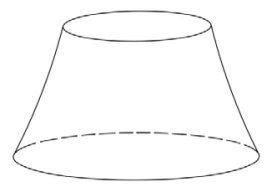

Fig. 1. Oval shape of described ore shoot.

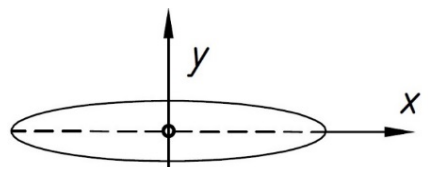

of Fig. 2. Horizontal cross section of ore shoot on plane $z=0$.

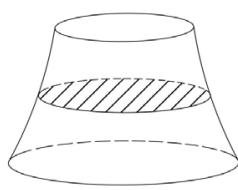

Fig. 3. Arbitrary horizontal cross section of ore shoot.

Geometric Fig. 2 is symmetrical relative to $O x$ and $O y$ axes. Therefore, area of the figure (Fig. 2) located in the first quadrant would be:

$$
\begin{gathered}
\frac{S}{4}=\int_{\pi / 2}^{0} y d x=\int_{\pi / 2}^{0} b \sin \varphi d(a \cos \varphi)=-\int_{\pi / 2}^{0} b \sin ^{2} \varphi d \varphi= \\
=-a b \int_{\pi / 2}^{0} \frac{1-\cos 2 \varphi}{2} d \varphi=-\left.\frac{1}{2} a b \varphi\right|_{\pi / 2} ^{0}+\left.\frac{1}{4} a b \sin 2 \varphi\right|_{\pi / 2} ^{0}=\frac{\pi}{4} a b .
\end{gathered}
$$

We obtain formula for calculating ellipse area:

$$
S=a b .
$$

Hence, the product of the semi-axes of the ellipse is the area of the ellipse.

Using this formula, we can calculate the area of any horizontal section of an elliptic hyperboloid (Fig. 3). Thys, the section of the surface (1) on the plane would be written as following:

$$
\frac{x^{2}}{a^{2}\left(\frac{z^{2}}{c^{2}}+1\right)}+\frac{y^{2}}{b^{2}\left(\frac{z^{2}}{c^{2}}+1\right)}=1,
$$

here $z$ is fixed value. Therefore, semi-axes of the ellipse shown in Fig. 3 would be written as following:

$$
a(z)=a \sqrt{\frac{z^{2}}{c^{2}}+1}, b(z)=b \sqrt{\frac{z^{2}}{c^{2}}+1},
$$

where $0 \leq z \leq h ; h$ is depth of ore shoot.

Using formula (4), area of the geometric figure from Fig. 3 is determined by following formula:

$$
S(z)=a b\left(\frac{z^{2}}{c^{2}}+1\right), 0 \leq z \leq h .
$$

Total volume of minerals is determined using following expression:

$$
V_{r}=\int_{0}^{h} S(z) d z
$$

Calculating this integral:

$$
V_{r}=a b \int_{0}^{h}\left(\frac{z^{2}}{c^{2}}+1\right) d z=\left.a b\left(\frac{z^{2}}{c^{2}}+1\right)\right|_{z=0} ^{z=h}=a b h\left(\frac{h_{2}}{3 c^{2}}+1\right) .
$$


Thus, the total volume of extracted ore would be:

$$
V_{r}=a b h\left(\frac{h_{2}}{3 c^{2}}+1\right)
$$

Assuming that on mining phase $t+1$ minerals are extracted from $z_{i}$ to $\mathrm{z}_{t+1}$ by $O z$ axis. In this case, volume of extracted ore would be calculated using formula:

$$
V_{r}(t+1)=a b \int_{z_{t}}^{z_{t+1}}\left(\frac{z^{2}}{c^{2}}+1\right) d z=\left.a b\left(\frac{z^{2}}{c^{2}}+1\right)\right|_{z=z_{t}} ^{z=z_{t+1}}=a b\left(\frac{z_{t+1}^{3}}{3 c^{2}}+z_{t+1}-\frac{z_{t}^{3}}{3 c^{2}}-z_{t}\right) .
$$

If $a$ and bare known (Fig. 2), then $c$ is calculated from the following equation:

$$
\frac{x^{2}}{a^{2}}+\frac{y^{2}}{b^{2}}=\frac{h^{2}}{c^{2}}+1
$$

It is an equation of a boundary of lower base of ore shoot from Fig. 1. In order to determine $c$, values of $a(n)$ or $b(n)$ should be known, where $a(n)$ is longitudinal semiaxis of ore shoot base; $b(n)$ is transverse semi-axis of ore shoot base. Taking $a(0)=a$ and using equation (5), we will have the following expression:

$$
a(n)=a(0) \sqrt{\frac{h^{2}}{c^{2}}+1} .
$$

We will obtain following expression by solving the last equation relative to $c$ :

$$
\frac{a^{2}(n)}{a^{2}(0)}-1=\frac{h^{2}}{c^{2}}
$$

Consequently

$$
c=\frac{a(0) h}{\sqrt{a^{2}(n)-a^{2}(0)}} .
$$

\subsection{Characteristics of oval shaped mineral occurrence by overburden}

We consider that only stripping works are performed at phase zero of mining. In this case, the overburden volume is an elongated cone, in which the long axis coincides with the longitudinal direction of the open pit mine, and the short axis coincides with the direction of the transverse axis of the open pit mine (Fig. 4). The depth of phase zero of stripping is set as $H$. Zero slope angle $\gamma_{0}$ of phase zero of stripping (Fig. 5). Surface of the cone would be:

$$
\frac{x^{2}}{A^{2}}+\frac{y^{2}}{B^{2}}=\frac{z^{2}}{C^{2}} \text {. }
$$

Equation of intersection line of a cone with plane $y=0$ is written as:

$$
\frac{x^{2}}{A^{2}}=\frac{z^{2}}{C^{2}} \text {. }
$$


or

$$
\left(\frac{x}{A}-\frac{z}{C}\right)\left(\frac{x}{A}+\frac{z}{C}\right)=0 .
$$

Then

$$
\frac{x}{A}-\frac{z}{C}=0
$$

Second line is symmetrical relative to $O z$ axis. We obtain following equation from Fig. 6:

$$
z=a_{0} \operatorname{tg} \gamma_{0}
$$

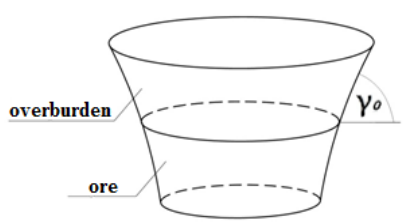

Fig. 4. 3D model of ore shoot with covering overburden rocks during phase zero of mining.

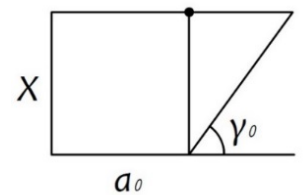

Fig. 5. Vertical longitudinal cross section of overburden during phase zero of mining.

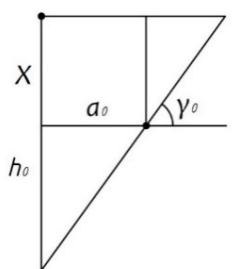

Fig. 6. Vertical longitudinal cross section of overburden (complemented to triangle).

We obtain coordinates of point $D\left(a_{0}, a_{0} t g \gamma_{0}\right)$. Line (10) passes through this point. Thus, we get:

$$
\frac{a_{0}}{A}-\frac{a_{0} \operatorname{tg} \gamma_{0}}{C}=0
$$

then

$$
C=A \operatorname{tg} \gamma_{0} \text { or } A=C \operatorname{ctg} \gamma_{0} .
$$

Reviewing cross section of a cone (9) on plane $x=0$, we obtain:

$$
A=\operatorname{Cctg} \sigma_{0} .
$$

Equations (11) and (12) are put into (9). Then we get the following equation:

$$
\frac{x^{2}}{C^{2} \operatorname{ctg}^{2} \gamma_{0}}+\frac{y^{2}}{C^{2} \operatorname{ctg}^{2} \sigma_{0}}=\frac{z^{2}}{c^{2}},
$$

or

$$
\left(x \operatorname{tg} \gamma_{0}\right)^{2}+\left(y \operatorname{tg} \sigma_{0}\right)^{2}=z^{2} .
$$

We obtain following equations from Fig. 7:

$$
h_{0}=a_{0} \operatorname{tg} \gamma_{0}, h_{0}=b_{0} \operatorname{tg} \sigma_{0} .
$$

Then

$$
\operatorname{tg} \sigma_{0}=\frac{a_{0}}{b_{0}} \operatorname{tg} \gamma_{0}
$$

Putting into (13), we get following equation: 


$$
x^{2} \operatorname{tg}^{2} \gamma_{0}+y^{2} \frac{a_{0}^{2}}{b_{0}^{2}} \operatorname{tg}^{2} \gamma_{0}=z^{2}
$$

or

$$
\frac{x^{2}}{a_{0}^{2}}+\frac{y^{2}}{b_{0}^{2}}=\frac{z^{2}}{h_{0}^{2}}
$$

In general case, equation of cone corresponding to phase tis written as:

$$
\frac{x^{2}}{a_{t}^{2}}+\frac{y^{2}}{b_{t}^{2}}=\frac{z^{2}}{h_{t}^{2}}, t=0,1,2, \ldots, n \text {. }
$$

where $h_{t}=a_{t} \operatorname{tg} \gamma_{t}$.

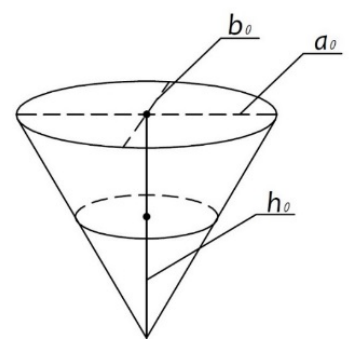

Fig. 7. Complemented overburden frustum.

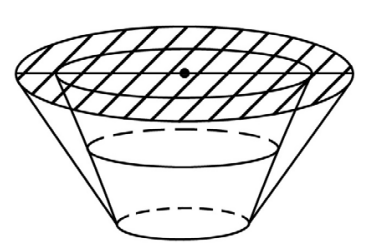

Fig. 8. 3D model view after first mining phase.

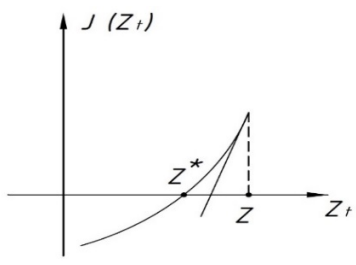

Fig. 9. Outline of solving cubic equation.

Volume of frustum corresponding to phase $t$ is determined by the following formula:

$$
V_{g m}(t)=\int_{z_{t}}^{z_{t+1}} S(z) d z
$$

here $V_{g m}(t)$ is volume of rock mass (overburden and minerals), extracted during phase $t$. Area of a transverse section of the cone is an ellipse (Fig. 8). Thus, using canonical formula (14), we obtain:

$$
S(z)=\frac{a_{t} b_{t}}{h_{t}} z^{2}
$$

Putting it into formula of $V_{g m}$, we get:

$$
V_{g m}(t)=\frac{a_{t} b_{t}}{h_{t}} \int_{h_{t}}^{z_{i}+H} z^{2} d z=\left.\frac{a_{t} b_{t}}{h_{t}} \frac{z^{3}}{3}\right|_{h_{t}} ^{z_{t}+H}=\frac{1}{3} b_{t} \operatorname{ctg} \gamma_{t}\left[\left(z_{t}+H\right)^{3}-h_{t}^{3}\right],
$$

with $t=0,1,2, \ldots, n$.

If $t=n$, then we get a formula for calculation of total volume of rock mass:

$$
V_{b}(n)=\frac{1}{3} b_{n} \operatorname{ctg} \gamma_{n}\left[(h+H)^{3}-h_{n}^{3}\right], \text { here } h_{n}=a_{n} \operatorname{tg} \gamma_{n} .
$$

The overburden volume is determined by the following formula during phase zero:

$$
V_{b}(1)=V_{g m}(1)-V_{g m}(0)-V_{r}(1)
$$

The overburden volume during next phase (Fig. 9) would be: 


$$
V_{b}(2)=V_{g m}(2)-V_{g m}(1)-V_{r}(2) .
$$

Using principle of mathematic induction, we derive general formula:

$$
V_{b}(t)=V_{g m}(t)-V_{g m}(t-1)-V_{r}(t), t=0,1,2, \ldots, n .
$$

Setting values of $V_{b}(0), V_{r}$ taking $V_{b}=V_{b}(n)-V_{r}$ and solving optimization problem by dynamic programming method, optimum volumes of overburden and ore are determined during each mining phase:

$$
V_{b}^{*}(t), V_{r}^{*}(t), \quad t=1,2, \ldots, n .
$$

It should be noted that the solution of the optimization problem in $3 \mathrm{D}$ format in methodological terms does not differ from the 2D case. The latter is shown in scientific works $[14-16]$. We should work with optimal quantities. In this regard, we will omit the sign of optimality "*” in the sequel for convenience of writing. We will determine the optimal parameters of the pit contours by mining phases knowing the quantities indicated in (16).

Using formula (5) for a mining phase $t$, we get:

$$
\begin{gathered}
V_{r}(t+1)=\int_{z_{t}}^{z_{t+1}} S(z) d z=a_{0} b_{0} \int_{z_{t}}^{z_{t+1}}\left(\frac{z^{2}}{c^{2}}+1\right) d z=\left.a_{0} b_{0}\left(\frac{z^{3}}{3 c^{2}}+z\right)\right|_{z_{t}} ^{z_{t+1}}= \\
=a_{0} b_{0}\left(\frac{z_{t+1}^{3}}{3 c^{2}}+z_{t+1}-\frac{z_{t}^{3}}{3 c^{2}}-z_{t}\right) .
\end{gathered}
$$

Hence, the following formula is derived:

$$
V_{r}(t+1)=a_{0} b_{0}\left(\frac{z_{t+1}^{3}}{3 c^{2}}+z_{t+1}-\frac{z_{t}^{3}}{3 c^{2}}-z_{t}\right) .
$$

Optimum values are determined by solving cubic equation (17) with numeric method:

$$
z_{t+1}, \quad t=0,1,2, \ldots, n-1
$$

It should be noted that $z_{0}=0$.

Equation (17) has single solution. We rewrite (17) to prove it:

$$
f\left(z_{t+1}\right)=a_{0} b_{0}\left(\frac{z_{t+1}^{3}}{3 c^{2}}+z_{t+1}-\frac{z_{t}^{3}}{3 c^{2}}-z_{t}\right)-V_{r}(t+1) .
$$

First derivative of this equation:

$$
f^{\prime}\left(z_{t+1}\right)=a_{0} b_{0}\left(\frac{z_{t+1}^{3}}{c^{2}}+1\right) .
$$

Second derivative:

$$
f^{\prime \prime}\left(z_{t+1}\right)=\frac{2}{3} a_{0} b_{0} z_{t+1}
$$

Inequalities $f^{\prime}\left(z_{t+1}\right)>0$ and $f^{\prime \prime}\left(z_{t+1}\right)>0$ hold for all values of $z_{t+1}>0$. Inequality 
$f^{\prime}\left(z_{t+1}\right)>0$ shows that function $y=f\left(z_{t+1}\right)$ is increasing; $f^{\prime \prime}\left(z_{t+1}\right)>0$ - graph of this function is a concave line. It follows from Fig. 9 that equation (17) has single solution. Root of this equation is determined by method of Newton. We could take $z$ (see Fig. 9) as a starting point.

Following equations are solved to find optimal values of $a_{i}$ and $b_{i}$ :

$$
\frac{a_{t+1}^{2}}{a_{0}^{2}}+\frac{a_{t+1}^{2}}{c^{2}}+1, \frac{b_{t+1}^{2}}{b_{0}^{2}}+\frac{z_{t+1}^{2}}{c^{2}}+1
$$

Then

$$
a_{t+1}=a_{0} \sqrt{\frac{z_{t+1}^{2}}{c^{2}}+1}, \quad b_{t+1}=b_{0} \sqrt{\frac{z_{t+1}^{2}}{c^{2}}+1}, \quad t=0,1,2, \ldots, n-1 .
$$

We use formula (15) to find optimal values of angles $\gamma_{t}$ and $\sigma_{t}$. Rewriting it:

$$
\begin{gathered}
V_{b}(t)=b_{t} \operatorname{ctg} \gamma_{t}\left[\left(z_{t}+H\right)^{3}-h_{t}^{3}\right]-b_{t-1} \operatorname{ctg} \gamma_{t-1}\left[\left(z_{t-1}+H\right)^{3}-h_{t-1}^{3}\right]- \\
-a_{0} b_{0}\left(\frac{z_{t}^{3}}{3 c^{2}}+z_{t}-\frac{z_{t-1}^{3}}{3 c^{2}}-z_{t-1}\right) .
\end{gathered}
$$

In this equation $h_{t}=a_{t} \operatorname{tg} \gamma_{t}$. Using expression:

$$
A_{t}=\frac{b_{t-1}}{b_{t}} \operatorname{ctg}\left(\gamma_{t-1}\right)\left[\left(z_{t-1}+H\right)^{3}-h_{t-1}^{3}\right]-\frac{1}{b_{t}} V_{r}(t), h_{t-1}=a_{t-1} \operatorname{tg}\left(\gamma_{t-1}\right), \quad t=1,2, \ldots, n-1 .
$$

A cubic equation is obtained relative $f_{t}=\operatorname{tg} \gamma_{t}$ :

$$
a_{0}^{3} f_{t}^{3}+A_{i} f_{t}-\left(z_{t}+H\right)^{3}=0 .
$$

The $f_{t}$ is determined at $t=1,2, \ldots, n-1$.

Optimal values of slope angles of open pit edges in longitudinal direction are determined by following expression using solution of cubic equations:

$$
\gamma_{t}=\operatorname{arctg}\left(f_{t}\right), t=1,2, \ldots, n-1 .
$$

We will use following equations to find slope angles in transverse direction of open pit contours:

$$
a_{t} \operatorname{tg}\left(\gamma_{t}\right)=b_{t} \operatorname{tg}\left(\sigma_{t}\right), \quad t=1,2, \ldots, n-1
$$

The $\sigma_{t}$ is determined at $t=0,1,2, \ldots, n-1, n$.

We will use following variables to find external dimensions of oval shaped open pit mines: $M_{t}$ is ellipse axis on its surface in longitudinal direction, $N_{t}$ is ellipse axis on its surface in transverse direction (Fig. 10). Trigonometric equations are derived to find parameters of interest using optimal values of $z_{t}, \gamma_{t}$ and $\sigma_{t}$.

$$
M_{t}=a_{t}+\left(z_{t}+H\right) \operatorname{tg} \gamma_{t} ; \quad N_{t}=b_{t}+\left(z_{t}+H\right) \operatorname{tg} \sigma_{t},
$$

where $t=0,1,2, \ldots, n-1, n$. 


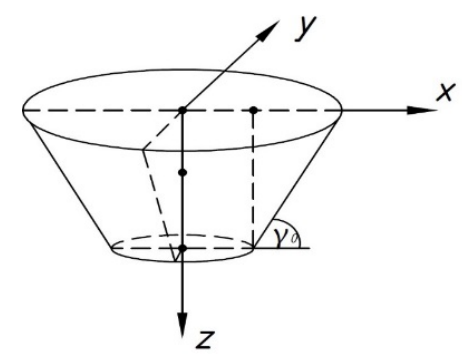

Fig. 10. Vertical and longitudinal transverse section for determining $M_{t}$ and $N_{t}$.

The analytical dependences of the phased overburden and ore volumes for the ovalshaped open pit mines were first obtained for the purpose of using the developed non-linear optimal control method conceptually described below in design practice.

\section{Results and discussion}

\subsection{Method of solving the problem of nonlinear optimal control during optimization of mining steeply dipping ore shoot}

Optimization of the mining operations mode for the created 3D model of phased mining of steeply dipping mineral occurrences has its own peculiarities. It is necessary to ensure an even distribution of ore reserves being extracted with the minimization of the phased stripping ratio on the perimeter of the open pit edges during each mining phase.

Let $S_{w}$ be a total volume of extracted rock mass, $S_{r}$ is volume of extracted ore, $u(t)$ is volume of extracted rock mass during phase $t, v(t)$ is volume of extracted ore during phase $t$, then stripping ratio would be determined by using following formula:

$$
k(t)=\frac{u(t)}{v(t)}, t=1,2, \ldots, n .
$$

It is known that for positive values of $u(t)$ and $v(t)$ minimum values of functions $k(t)$ and $k^{2}(t)$ are reached in the same points in the domain of functions $u(t)$ and $v(t)$. Thus, further we will solve the following problem:

$$
J(u, t)=\sum_{t=1}^{n} \frac{u^{2}(t)}{v^{2}(t)} \rightarrow \min .
$$

It follows from a practical standpoint of rock mass volume $u(t)$, that volume of rock mass should be minimum during each phase. On the other hand, from mining operations technology standpoint, all volume of rock mass and ore should be extracted during last phase $n$. Thus, we derive following expressions:

$$
x(t)=x(t-1)+u(t), y(t)=y(t-1)+v(t), \quad t=1,2, \ldots, n,
$$

where $x(t)$ is total volume of extracted rock mass including phase $t ; y(t)$ is total volume of extracted ore during phase $t$.

We also have following equations:

$$
x(n)=S_{w}, \quad y(n)=S_{r} .
$$

Setting $x(0)$ as volume of extracted rock mass during phase zero of mining, $y(0)$ is volume of extracted ore during phase zero of mining. Therefore, we get: 


$$
\begin{gathered}
x(t) \in\left[x(0) ; S_{w}\right] \equiv X, y(t) \in\left[y(0) ; S_{r}\right] \equiv Y, \\
u(t) \in\left[0 ; S_{w}-x(0)\right] \equiv U, v(t) \in\left[0 ; S_{r}-y(0)\right] \equiv V,
\end{gathered}
$$

here $X, Y$ and $U, V$ are permissible values of states $x(t), y(t)$ and controls $u(t), v(t)$. It means, that optimum solution of systems (19)-(21) should be found including following expression:

$$
x^{*}(t) \in X, y^{*}(t) \in Y, u^{*}(t) \in U, v^{*}(t) \in V, t=1,2,3, \ldots, n .
$$

Vector notation is used sometimes:

$$
\vec{x}=(x(0), x(1), \ldots, x(n)), \vec{y}=(y(0), y(1), \ldots, y(n)) .
$$

In our case these are states of extracted rock mass and ore volumes. Each component of vectors $\vec{x}, \vec{y}$ has positive value, with following inequality:

$$
x(0)<x(1)<x(2)<\ldots<x(n), y(0)<y(1)<y(2)<\ldots<y(n) .
$$

Similarly, $\vec{u}=(u(1), u(2), \ldots, u(n)), \quad v=(v(1), v(2), \ldots, v(n))-$ group of control vectors, which is called control (management) of mining operations.

Function $J(u, v)$ is separable. Hence, dynamic programming method developed by Bellman [18-21] was used to minimise function (18). Its implementation is described in the scientific works [22-24].

\section{Conclusions}

A 3D model for the phased development of contours has been created for oval shaped open pit mines. The volumetric contour of the mineral was interpolated by an elliptical hyperboloid of the oval form. It is assumed that such a method of interpolation satisfies the practice of open pit mining steeply dipping oval mineral occurrences when developing a working zone along steep open pit edges without temporary non-operating open pit edges with sufficient accuracy. It is clear that the functional type of interpolation and the substantiation of its reliability is an independent task. It is necessary to use the actual data of the studied digital model of the open pit mine. The optimal control problem discussed in this paper depends on the solution of the cubic equation of nonlinear algebra. It was proven that the cubic equation has a unique solution. This fact indirectly proves the correctness of the chosen method of solving the studied problem. The algorithm for solving the cubic equation developed in this paper is very simple. It can be implemented using any programming language, in particular $\mathrm{C}++$ or Java. Using the roots of cubic equations, the optimum values of the stripping ratio, the slope angles of the open pit edges and the volumes of stripping operations are determined, depending on the mining phase. The resulting 3D model extends the horizons of object-oriented modeling using integrated information complexes and digital field models.

We would like to thank all the members of the research group for their participation in preparing this article.

\section{References}

1. Moldabayev, S., Rysbayuly, B., Sultanbekova, Z., \& Sarybayev, N. (2016). 3D modeling of phased development of mining operations on steeply dipping round deposits. In 6 th International 
Conference on Computer Applications in the Minerals Industries Istanbul (CAMI 2016). Istanbul, Turkey, (43), 5.

2. Moldabayev, S.K., Rysbayuly, B., Sultanbekova, Z.Z., \& Sarybayev, N.O. (2016). Creation of a 3D model of development of open pit mining steeply dipping round open pit mines. Heotekhnichna Mekhanika, (129), 82-91.

3. Moldabayev, S., Rysbayuly, B., Sultanbekova, Z., Aben, Y., \& Sarybayev, N. (2016). Dynamic model of new order of working zone forming realization on steep boards of oval form quarries. 6th International Conference on Computer Applications in the Minerals Industries (CAMI 2016). Istanbul, Turkey, (20), 7.

4. Askari-Nasab, H., Frimpongt, S., \& Szymanski, J. (2008). Inverstigating continuous time open pit dynamics. The Journal of the Southern African Institute of Mining and Metallurgy, 63-71.

5. Elahi zeyni, E., Kakaie, R., \& Yousefi, A. (2011) A new algorithm for optimum open pit design: Floating cone method III. Journal of Mining \& Environment, (2/2), 118-125.

6. Souza, M.J.F., Coelho, I.M., Ribas, S., Santos, H.G., \& Merschmann, L.H.C. (2010). A hybrid heuristic algorithm for the open-pit-mining operational planning problem. European Journal of Operational Research, 207(2), 1041-1051. https://doi.org/10.1016/j.ejor.2010.05.031

7. Belov, O., Shustov, O., Adamchuk, A., \& Hladun, O. (2018). Complex Processing of Brown Coal in Ukraine: History, Experience, Practice, Prospects. Solid State Phenomena, (277), 251-268. https://doi.org/10.4028/www.scientific.net/ssp.277.251

8. Dryzhenko, A., Shustov, A., \& Moldabayev, S. (2017). Justification of parameters of building inclined trenches using belt conveyors. International Multidisciplinary Scientific GeoConference Surveying Geology and Mining Ecology Management, SGEM, 17(13), 471-478.

9. Kalybekov, T., Rysbekov, K., \& Zhakypbek, Y. (2015). Efficient land use in open-cut mining. New Developments in Mining Engineering 2015: Theoretical and Practical Solutions of Mineral Resources Mining, 287-291. https://doi.org/10.1201/b19901-51

10. Cherniaiev, O.V. (2017). Systematization of the hard rock non-metallic mineral deposits for improvement of their mining technologies. Naukovyi Visnyk Natsionalnoho Hirnychoho Universytetu, (5), 11-17.

11. Dryzhenko, A., Moldabayev, S., Shustov, A., Adamchuk, A., \& Sarybayev, N. (2017). Open pit mining technology of steeply dipping mineral occurences by steeply inclined sublayers. International Multidisciplinary Scientific GeoConference Surveying Geology and Mining Ecology Management, SGEM, 17(13), 599-606. https://doi.org/10.5593/sgem2017/13/s03.076

12. Malanchuk, Z.R. (2019). Substantiating parameters of zeolite-smectite puff-stone washout and migration within an extraction chamber. Naukovyi Visnyk Natsionalnoho Hirnychoho Universytetu, (6). Accepted paper.

13. Morales, N., \& Reyes, P. (2016). Increasing the value and feasibility of open pit plans by integrating the mining system into the planning process. Journal of the Southern African Institute of Mining and Metallurgy, 116(7), 663-672. https://doi.org/10.17159/2411-9717/2016/v116n7a8

14. Saavedra-Rosas, J., Jelvez, E., Amaya, J., \& Morales, N. (2016). Optimizing open-pit block scheduling with exposed ore reserve. Journal of the Southern African Institute of Mining and Metallurgy, 116(7), 655-662. https://doi.org/10.17159/2411-9717/2016/v116n7a7

15. Samavati, M., Essam, D., Nehring, M., \& Sarker, R. (2017). A local branching heuristic for the open pit mine production scheduling problem. European Journal of Operational Research, 257(1), 261-271. https://doi.org/10.1016/j.ejor.2016.07.004

16. Moldabayev, S., \& Aben, E. (2016). New technology production mining on a steep board deep pits. International Journal of Applied Engineering Research: Research India Publications, (22), 10458-10464.

17. Rakishev, B.R., \& Moldabayev, S.K. (2015). Justification of formation order of working zones on deep open pit mines with excavator-automobile complexes. Mining Informational and Analytical Bulletin, (1), 27-34.

18. Diwekar, U. (2008). Introduction to Applied Optimization. New York: Springer. 
19. Hillier, F.S., \& Lieberman, G.J. (2014). Introduction to Operations Research. McGraw Hill Higher Education.

20. Antoniou, A., \& Lu, W.-S. (2007). Practical Optimization. Algorithms and Engineering Applications. New York: Springer.

21. Fu, M.C. (2015). Handbook of Simulation Optimization. New York: Springer.

22. Moldabayev, S.K., Rysbaiuy, B., \& Sultanbekova, Zh.Zh. (2013). Justification of Countours Belonging to the Stages of Mining Steeply Dipping Deposits Using the Solution of the Problem of Nonlinear programming. Proceedings of the $22^{\text {nd }}$ MPES Conference. Mine Planning and Equipment Selection. Dresden, (1), 125-132.

23. Moldabayev, S., \& Rysbaiuly, B. (2015). Solution of nonlinear programming problem by Bellman method while optimizing the two-level mining of benches in deep open pits. New Developments in Mining Engineering 2015: Theoretical and Practical Solutions of Mineral Resources Mining, 49-53. https://doi.org/10.1201/b19901-10

24. Moldabayev, S.K., Rysbaiuly, B., \& Sultanbekova, Z.Z. (2015). Automation of calculation of optimal parameters of two-level mining of benches with cross-section panels by excavator-auto truck complexes. The $23^{\text {rd }}$ International symposium on mine planning \& equipment selection. Johannesburg, South Africa, 1139-1146. 